\title{
Study on Management and Control of a District Heating and Cooling Plant
}

\author{
Toshiki Doyama ${ }^{1,5}$, Michihiro Kondo ${ }^{2}$, Hiroshi Imaoka ${ }^{1}$, \\ Daisuke Sumiyoshi ${ }^{3}$, Hiroki Kitayama ${ }^{4}$, Jongyeon Lim ${ }^{5}$, and Yasunori Akashi ${ }^{5}$ \\ ${ }^{1}$ Kyudenko Corporation, Fukuoka, Japan \\ ${ }^{2}$ Fukuoka Energy Service Co., Inc., Fukuoka, Japan \\ ${ }^{3}$ Kyushu University, Fukuoka, Japan \\ ${ }^{4}$ Kyushu Sangyo University, Fukuoka, Japan \\ ${ }^{5}$ The University of Tokyo, Tokyo, Japan
}

\begin{abstract}
Recently, the district heating and cooling (DHC) system has attracted attention for energy saving. Although regional conduit, which contains a large amount of water, is considered as a kind of heat storage tank, an inner flow state has not been minutely analysed. In this study, by development of a regional conduit model, spatiotemporal change of internal energy is estimated. Simulation results show that the temperature change at small diameter pipe before customer receiving facilities is half of the whole temperature loss in regional conduit. This implies that optimal management of receiving flow rate is necessary.
\end{abstract}

\section{Introduction}

The Government of Japan has supported DHC projects for promoting a regional use of energy toward establishing low-carbon urban structures. In DHC, the heat supply agreement should be observed for all customers, which leads to an important issue today for renewal of old DHC plants. Especially in a suburb-type DHC, because of not much increase of heat supply buildings and load since completion, the heat source system has been overdesigned. Unlike the case of new construction, in renewal, underground buried regional conduit should continue to be used. This means that the analysis of detailed behaviour of water in regional conduit is important for catching operational problems that had passed before. The aim of this study is, as an example of an old suburb-type DHC plant, to propose a new management and control method of DHC including customers as well as plants. First, we investigate the flow pattern of water in regional conduit, and then, calculate the internal energy loss based on assumption of regional conduit to be a heat storage tank.

\section{Plant summary}

The Seaside Momochi DHC plant in Fukuoka, which is composed of two plants, has been operated for more than 25 years since April 1993 (Figure 1). Three 3000 USRt seawater-source heat pumps at the 1 st plant are mainly

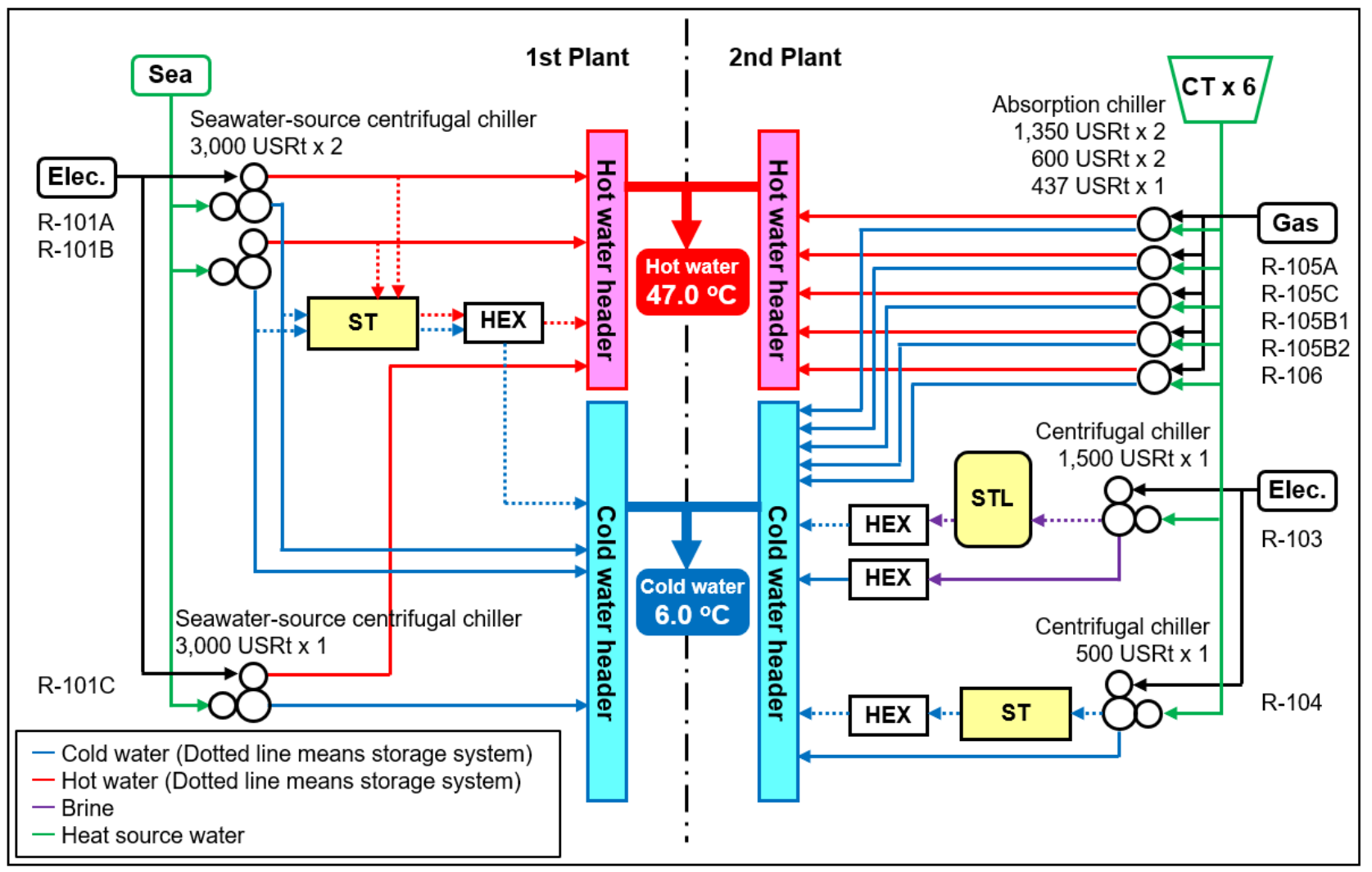

Figure 1: Current system flowchart of target DHC plant. 


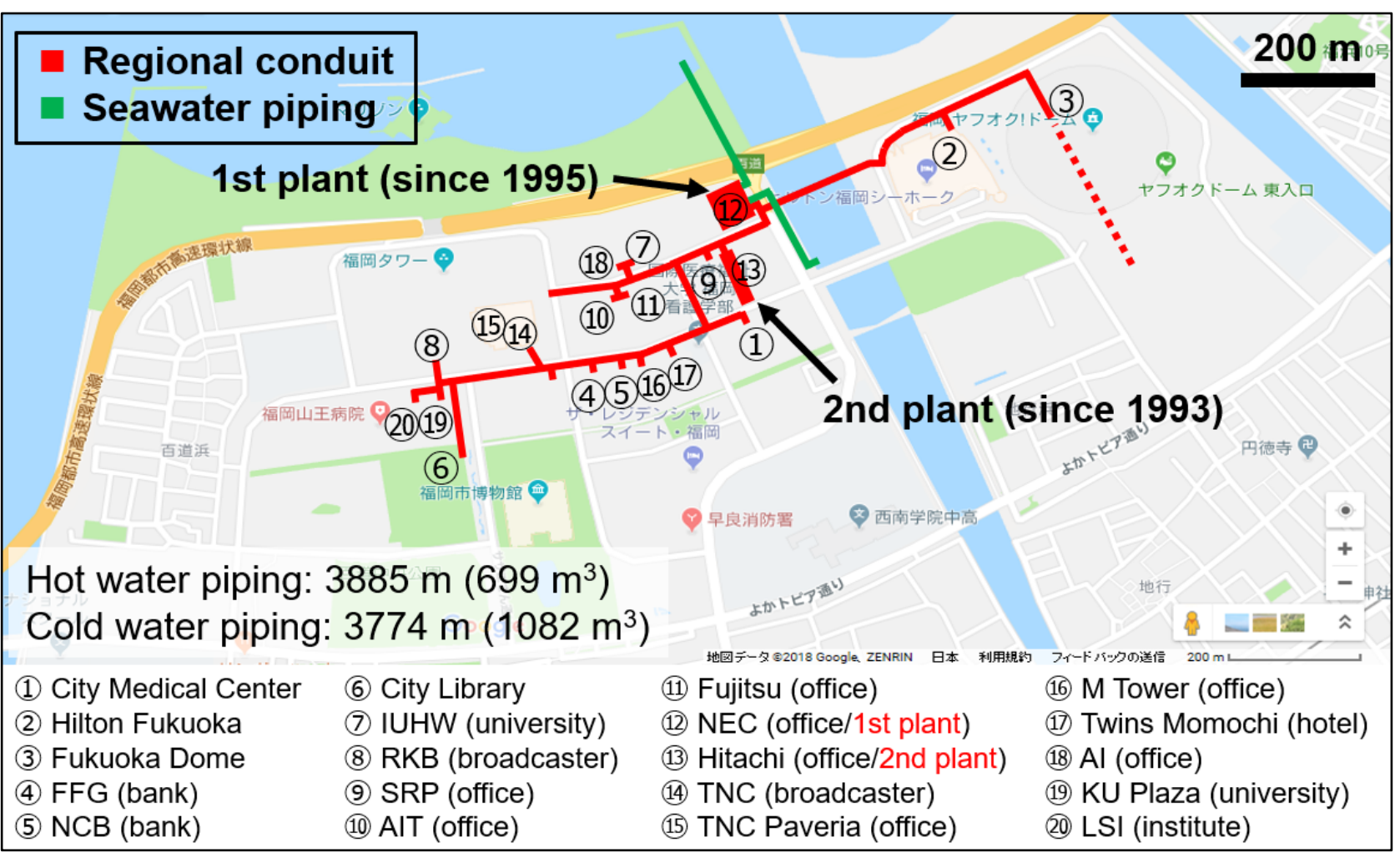

Figure 2: Supply buildings and regional conduit piping.

operated throughout the years and still as they were at the completion. Cold and hot water is supplied to 20 buildings through underground regional conduit, and the supply and return temperature of the heat supply agreement is respectively 6.0 to $12.0{ }^{\circ} \mathrm{C}$ for cold water and 47.0 to $40.0^{\circ} \mathrm{C}$ for hot water (Kondo et al., 2018).

Seawater-source heat pumps at the 1st plant have the highest priority of operation, which are currently in base operation throughout the year, and nearly 90 percent of annual heat production amount is dependent on these machines. On the other hand, absorption heat pumps at the 2nd plant are mainly operated at the peak load, which contributes to electric power peak-cut. Seawater-source heat pumps correspond to heat storage operation, and a heat storage tank is $4000 \mathrm{~m}^{3}$ at the $1 \mathrm{st}$ plant and $1900 \mathrm{~m}^{3}$ at the 2 nd plant. In water supply system, about 15 percent of cold water volume in supply header is bypassed to return header, and around 35 percent of hot water volume is also bypassed, which should be minimized. The operation period with the temperature difference secured is about $3000 \mathrm{~h} /$ year for cold water and nearly $1000 \mathrm{~h} /$ year for hot water. The total length of regional conduit is 3774 $\mathrm{m}$ for cold water and $3885 \mathrm{~m}$ for hot water. The holding volume is $1082 \mathrm{~m}^{3}$ for cold water and $699 \mathrm{~m}^{3}$ for hot water, which could be considered as a small heat storage tank. Although hot water piping is insulated, cold water piping is not insulated (Doyama et al., 2018).

\section{Methods}

\section{Flow balance model}

In water supply system, pump head is dependent on pressure loss through regional conduit and customer

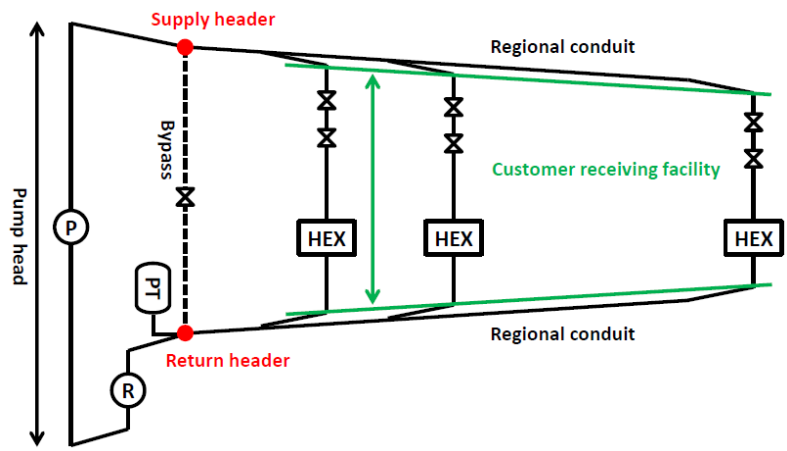

Figure 3: Water supply system flowchart.

receiving facilities as well as piping and refrigerators inside plant (Figure 3). At customer facility, a pressure control valve, automatic flow volume control valve, and heat exchanger are introduced on regional conduit. A pressure tank is connected to return header inside plant, where gauge pressure is controlled. In order to estimate pressure distribution in regional conduit, a flow balance at all sections of conduit is analysed for supply and return piping. Input data are customer's receiving water flow volume $\left[\mathrm{m}^{3} / \mathrm{h}\right]$, which are 30 -minute data, and plant supply flow volume $\left[\mathrm{m}^{3} / \mathrm{h}\right]$ and header bypass flow volume $\left[\mathrm{m}^{3} / \mathrm{h}\right]$, which are 60 -minute data. In flow balance, in order to adjust the resolution of data, 30-minute data are converted to 60-minute data.

The 1st and 2nd plant are connected by bypass piping, where a water flow direction is varied by flow balance in the whole conduit (Figure 4). The flow is divided into five patterns, and in some cases, the velocity at bypass piping is very slow and the conduit becomes like a storage tank. 


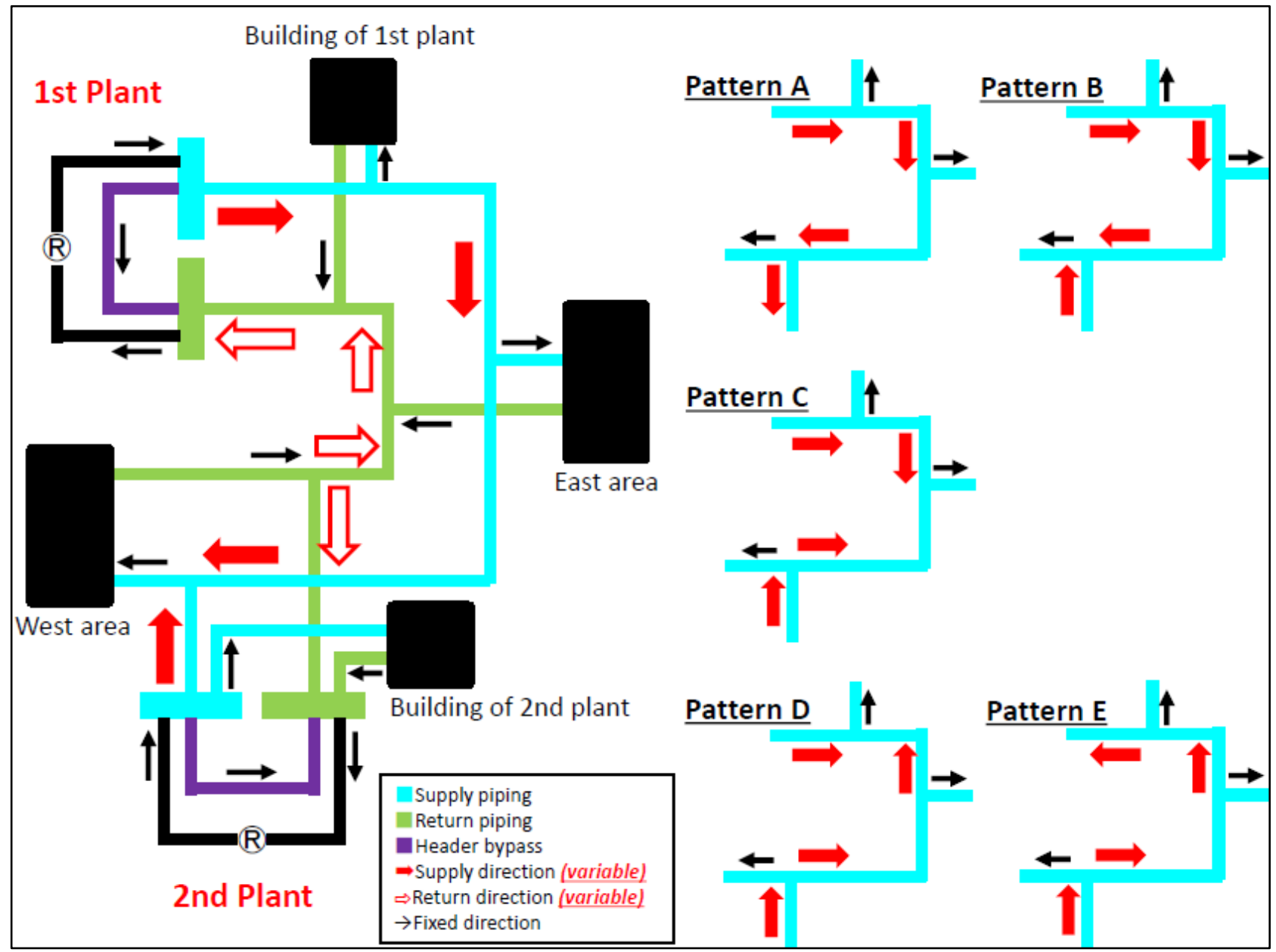

Figure 4: Flow patterns in regional conduit.

The pattern $\mathrm{A} / \mathrm{E}$ is the case that the $1 \mathrm{st} / 2 \mathrm{nd}$ plant alone is in operation. The pattern $\mathrm{B}$, which is common in the target DHC plant, is the case that the 1st plant is mainly operated and covers east area demand. When east area demand is very high and above the 1 st plant supply, the pattern B becomes $\mathrm{C}$, which frequently occurs on the peak time. In this case, the velocity at the bypass piping is relatively slow. The pattern $\mathrm{D}$ is a rare case in the target plant. These five flow patterns are decided by flow balance of all customers' receiving water flow volume. Energy loss in regional conduit is calculated based on the flow pattern.

First, at each time step, which of the five patterns A-E the current flow pattern is classified as is determined. The end point of calculation of pressure and temperature loss depends on the flow pattern. If the 2 nd/1st plant supply $(\mathrm{P} 2 / \mathrm{P} 1)$ is equal to zero $(\mathrm{P} 2 / \mathrm{P} 1=0)$, the pattern $\mathrm{A} / \mathrm{E}$ occurs. Also, if P2 is lower than the sum of the 2nd plant header bypass (H2) and building receiving (B2) volume $(\mathrm{P} 2<\mathrm{H} 2+\mathrm{B} 2)$, the pattern A occurs. If $\mathrm{P} 1$ is lower than the 1st plant header bypass volume $(\mathrm{H} 1)(\mathrm{P} 1<\mathrm{H} 1)$, the pattern E also appears. Otherwise, if the 1st plant building receiving volume (B1) is lower than the subtraction of $\mathrm{P} 1$ and $\mathrm{H} 1(\mathrm{~B} 1<\mathrm{P} 1-\mathrm{H} 1)$, and the west area demand $(\mathrm{W})$ is larger than the subtraction of $\mathrm{P} 2, \mathrm{H} 2$, and $\mathrm{B} 2$ (W>P2-H2$\mathrm{B} 2$ ), the pattern B occurs. In the same way, if $\mathrm{B} 1</>\mathrm{P} 1-$ $\mathrm{H} 1$ and $\mathrm{W}<\mathrm{P} 2-\mathrm{H} 2-\mathrm{B} 2$, the pattern $\mathrm{C} / \mathrm{D}$ appears.
Then, at each section of conduit, the flow volume $\mathbf{d}$ is calculated as follows.

$$
\mathbf{A} \mathbf{c}=\mathbf{d}
$$

where $\mathbf{c}$ is the vector $(20 \times 1)$ of all customers' receiving flow volume, and $\mathbf{d}$ is the vector $(45 \times 1)$ of flow volume at all sections of conduit. $\mathbf{A}$ is the flow path matrix $(45 \times 20)$ that consists only of 0 and 1 and varies with the flow pattern. Based on flow volume distribution, pressure and temperature loss could be estimated.

\section{Regional conduit model}

In order to simulate energy loss in regional conduit, thermal hydraulics is applied to inner flow inside circular pipe (Nakayama et al., 2002). By supposition of axial symmetry, the cylindrical coordinate system is adopted. The $x$-axis is set in the flow direction, and the $r$-axis is set in the radial direction (Figure 5). On the assumption that water is incompressible fluid, the water density $\rho\left[\mathrm{kg} / \mathrm{m}^{3}\right]$ is constant for time and space regardless of temperature. For simplification of calculation, the kinematic viscosity $v\left[\mathrm{~m}^{2} / \mathrm{s}\right]$ and the thermal diffusivity $\alpha\left[\mathrm{m}^{2} / \mathrm{s}\right]$ of water are constant for space regardless of temperature. In this study, the velocity field is supposed to be fully developed, and the $x$-direction velocity $U[\mathrm{~m} / \mathrm{s}]$ becomes constant for space. 
In inner flow analysis, dominant equations are three kinds of differential equations for continuity, momentum, and energy. Firstly, the equation of continuity is written as

$$
\frac{\partial U}{\partial x}+\frac{1}{r} \frac{\partial(r V)}{\partial r}=0
$$

Secondly, the equations of momentum are written as

$$
\begin{aligned}
& \frac{\partial U}{\partial t}+\frac{\partial(U U)}{\partial x}+\frac{1}{r} \frac{\partial(r V U)}{\partial r} \\
=- & \frac{1}{\rho} \frac{\partial P}{\partial x}+v \frac{\partial^{2} U}{\partial x^{2}}+\frac{v}{r} \frac{\partial}{\partial r}\left(r \frac{\partial U}{\partial r}\right) \\
& \frac{\partial V}{\partial t}+\frac{\partial(U V)}{\partial x}+\frac{1}{r} \frac{\partial(r V V)}{\partial r} \\
=- & \frac{1}{\rho} \frac{\partial P}{\partial r}+v \frac{\partial^{2} V}{\partial x^{2}}+\frac{v}{r} \frac{\partial}{\partial r}\left(r \frac{\partial V}{\partial r}\right)-\frac{v V}{r^{2}}
\end{aligned}
$$

Thirdly, the equation of energy is written as

$$
\frac{\partial T}{\partial t}+\frac{\partial(U T)}{\partial x}+\frac{1}{r} \frac{\partial(r V T)}{\partial r}=\alpha \frac{\partial^{2} T}{\partial x^{2}}+\frac{\alpha}{r} \frac{\partial}{\partial r}\left(r \frac{\partial T}{\partial r}\right)
$$

where $U$ and $V$ is respectively $x$ - and $r$-direction velocity $[\mathrm{m} / \mathrm{s}]$, and $P$ is pressure $[\mathrm{Pa}]$, and $T$ is temperature $[\mathrm{K}]$. Independent variables are $x[\mathrm{~m}], r[\mathrm{~m}]$, and $t[\mathrm{~s}]$. From the boundary condition of no-slip at pipe wall and the constant $U$, the equation (2) gives the $r$-direction velocity $V=0$. Therefore, the equations (3) and (4) respectively become

$$
\begin{gathered}
\frac{\partial U}{\partial t}=-\frac{1}{\rho} \frac{\partial P}{\partial x}+\frac{v}{r} \frac{\partial}{\partial r}\left(r \frac{\partial U}{\partial r}\right) \\
\frac{\partial V}{\partial t}=-\frac{1}{\rho} \frac{\partial P}{\partial r}=0
\end{gathered}
$$

The equation (5) becomes

$$
\frac{\partial T}{\partial t}+U \frac{\partial T}{\partial x}=\alpha \frac{\partial^{2} T}{\partial x^{2}}+\frac{\alpha}{r} \frac{\partial}{\partial r}\left(r \frac{\partial T}{\partial r}\right)
$$

The equation (7) means that $P$ is independent of $r$. If $U$ and $T$ could be represented by a value independent of $r$, the equations (6) and (8) are simplified. By integral across pipe cross-section, the cross-section-averaged equations are introduced, and $r$ is cleared. The equations (6) and (8) respectively become as follows.

$$
\begin{gathered}
\frac{\partial U_{B}}{\partial t}=-\frac{1}{\rho} \frac{\partial P}{\partial x}+\frac{8 v U_{B}}{R_{0}^{2}} \\
\frac{\partial T_{B}}{\partial t}+U_{B} \frac{\partial T_{B}}{\partial x}=\alpha \frac{\partial^{2} T_{B}}{\partial x^{2}}+\frac{2 q}{R_{0} \rho c_{p}}
\end{gathered}
$$

where $U_{B}$ is the $x$-direction bulk mean velocity $[\mathrm{m} / \mathrm{s}]$, and $T_{B}$ is the bulk mean temperature [K]. For simplification, $U$ is assumed to be parabolic distribution such as a laminar flow. $R_{0}$ is the inner pipe radius [m]. $c_{p}$ is constant pressure specific heat capacity of water $[\mathrm{J} / \mathrm{kgK}]$, and $q$ is the $r$ direction heat flux $\left[\mathrm{W} / \mathrm{m}^{2}\right]$.

$$
q=\frac{T_{G}-T_{B}}{\frac{1}{h_{0}}+\frac{R_{0} \ln \left(R_{1} / R_{0}\right)}{k_{1}}+\frac{R_{0} \ln \left(R_{2} / R_{1}\right)}{k_{2}}+\frac{R_{0} \ln \left(R_{G} / R_{2}\right)}{k_{G}}}
$$

where $T_{G}$ is ground surface temperature [K], and $R_{1}$ and $R_{2}$ is respectively the outer pipe radius and the outer radius of thermal insulation material [m], and $R_{G}$ is burial depth [m]. $h_{0}$ is heat transfer coefficient between water and pipe wall $\left[\mathrm{W} / \mathrm{m}^{2} \mathrm{~K}\right]$, and $k_{1}, k_{2}$, and $k_{G}$ are thermal conductivity

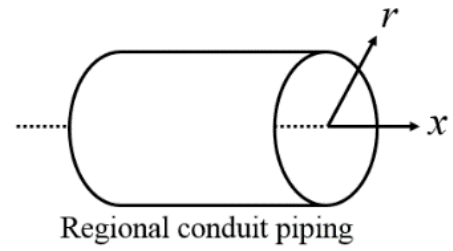

Figure 5: Cylindrical coordinate system.

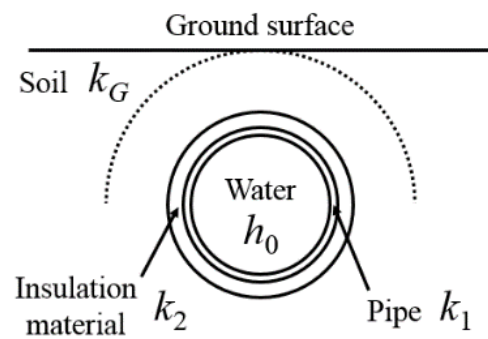

Figure 6: Underground sectional model of piping.

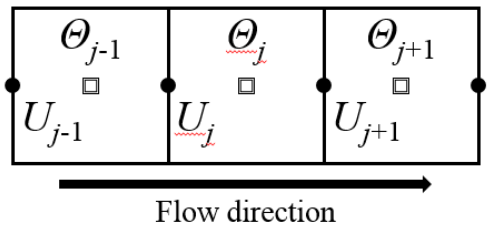

Figure 7: Staggered grid system.

of pipe, insulation material, and soil respectively [W/mK]. For simplification of model, heat input from flat ground surface is assumed to be heat flux from semi-circular surface, and that all the heat from ground equally spreads around the pipe circumference is supposed (Figure 6).

In this study, we convert the equations (9) and (10) to the dimensionless equations written as

$$
\begin{gathered}
\frac{\partial U_{B}^{*}}{\partial t^{*}}=Z^{*} \frac{\partial P^{*}}{\partial x^{*}}+\frac{32 U_{B}^{*}}{R_{0}^{*} \operatorname{Re}} \\
\frac{\partial \Theta_{B}^{*}}{\partial t^{*}}+U_{B}^{*} \frac{\partial \Theta_{B}^{*}}{\partial x^{*}}=\frac{R_{0}^{*}}{\operatorname{Re} \operatorname{Pr}} \frac{\partial^{2} \Theta_{B}^{*}}{\partial x^{* 2}} \\
+\frac{8 \mathrm{Nu}\left(\Theta_{G}^{*}-\Theta_{B}^{*}\right)}{R_{0}^{*} \operatorname{Re} \operatorname{Pr}\left(2+\mathrm{Nu} \sum_{i}\left(k_{0} / k_{i}\right) \ln \left(R_{i} / R_{i-1}\right)\right)}
\end{gathered}
$$

where $U_{B}^{*}, P^{*}, \Theta_{B}^{*}, \Theta_{G}^{*}, R_{0}^{*}, x^{*}$, and $t^{*}$ are normalized values defined as follows.

$$
\begin{gathered}
U_{B}^{*} \equiv \frac{U_{B}}{\bar{U}} \\
P^{*} \equiv \frac{P-\overline{P_{1}}}{\overline{P_{2}}-\overline{P_{1}}} \\
\Theta_{B}^{*} \equiv \frac{T_{B}-\overline{T_{1}}}{\overline{T_{2}}-\overline{T_{1}}}, \Theta_{G}^{*} \equiv \frac{T_{G}-\overline{T_{1}}}{\overline{T_{2}}-\overline{T_{1}}} \\
R_{0}^{*} \equiv \frac{R_{0}}{\bar{R}} \\
x^{*} \equiv \frac{x}{2 \bar{R}} \\
t^{*} \equiv \frac{t}{2 \bar{R} / \bar{U}}
\end{gathered}
$$

$\bar{U}$ is the reference velocity $[\mathrm{m} / \mathrm{s}]$ such as designed maximum velocity, and $2 \bar{R}$ is the reference length [m] such as maximum pipe diameter. $\overline{P_{1}}$ and $\overline{T_{1}}$ are 
respectively the first reference pressure $[\mathrm{Pa}]$ and temperature $[\mathrm{K}]$ such as supply water pressure and temperature, and $\overline{P_{2}}$ and $\overline{T_{2}}$ are respectively the second reference pressure $[\mathrm{Pa}]$ and temperature $[\mathrm{K}]$ such as return water pressure and temperature. $Z^{*}$ is written as

$$
Z^{*}=-\frac{\overline{P_{2}}-\overline{P_{1}}}{\rho \bar{U}^{2}}
$$

Reynolds number Re [-], Prandtl number Pr [-], and Nusselt number $\mathrm{Nu}[-]$ are defined as follows.

$$
\begin{gathered}
\operatorname{Re} \equiv \frac{2 R_{0} \bar{U}}{v} \\
\operatorname{Pr} \equiv \frac{v}{\alpha} \\
\mathrm{Nu} \equiv \frac{2 R_{0} h_{0}}{k_{0}}=\frac{2 R_{0} h_{0}}{\rho c_{p} \alpha}
\end{gathered}
$$

where $k_{0}$ is the thermal conductivity of water. To determine $h_{0}$ is very difficult, and Nusselt number $\mathrm{Nu}$ is given by a famous empirical formula of Dittus-Boelter's equation (1930) written as

$$
\mathrm{Nu}=0.023 \operatorname{Re}^{0.8} \operatorname{Pr}^{0.3 \sim 0.4}
$$

where the power exponent of $\mathrm{Pr}$ is supposed to be 0.4 for cold water and 0.3 for hot water.

In differentiation of equations, the staggered grid system is adopted with forward difference for time and central difference for space. For advection term, upwind difference is adopted for numerical stability. By solution of the equations (12) and (13) at each time step, unsteady energy loss simulation becomes possible (Figure 7). In this study, physical property values such as density are given by Table 1 , and calculation conditions such as integration time interval and boundary condition are shown in Table 2. Reference values indicated by overline are configured in Table 3. Particularly, for grid and integration time interval, the Courant number $C[-]$ becomes

$$
C=U \frac{\Delta t}{\Delta x} \leq \bar{U} \frac{\Delta t}{\Delta x}=0.9<1
$$

which certainly satisfies the Courant-Friedrichs-Lewy (CFL) condition.

\section{Results}

\section{Pressure loss}

For pressure in regional conduit, calculation results show that the pressure loss throughout conduit is very small, whereas a drastic loss is found at the customer receiving facilities. In Figure 8 and 9, cold and hot water pressure loss through supply and return conduit on the seasonal peak is plotted for all customers. For cold water, roundtrip pressure loss except at receiving facility is less than $150 \mathrm{kPa}$ all day. For hot water, except for one customer, round-trip pressure loss except at receiving facility is less than $50 \mathrm{kPa}$ all day. As for the remaining customer excluded, the pipe diameter branched from main conduit is small compared with demand flow volume, which would cause nearly $300 \mathrm{kPa}$ loss.
Table 1: Physical property values.

\begin{tabular}{|c|c|r|}
\hline Physical property & Symbol & \multicolumn{1}{c|}{ Value } \\
\hline Water density & $\rho$ & $\begin{array}{r}\text { cold) } 1000 \mathrm{~kg} / \mathrm{m}^{3} \\
\text { hot) } 990 \mathrm{~kg} / \mathrm{m}^{3}\end{array}$ \\
\hline $\begin{array}{c}\text { Kinematic viscosity } \\
\text { of water }\end{array}$ & $v$ & $\begin{array}{r}\text { cold) } 1.3 \times 10^{-6} \mathrm{~m}^{2} / \mathrm{s} \\
\text { hot) } 6.0 \times 10^{-7} \mathrm{~m}^{2} / \mathrm{s}\end{array}$ \\
\hline $\begin{array}{c}\text { Thermal diffusivity of } \\
\text { water }\end{array}$ & $\alpha$ & $\begin{array}{r}\text { cold) } 1.3 \times 10^{-7} \mathrm{~m}^{2} / \mathrm{s} \\
\text { hot) } 1.5 \times 10^{-7} \mathrm{~m}^{2} / \mathrm{s}\end{array}$ \\
\hline $\begin{array}{c}\text { Thermal conductivity } \\
\text { of water }\end{array}$ & $k_{0}$ & $\begin{array}{r}\text { cold) } 0.57 \mathrm{~W} / \mathrm{mK} \\
\text { hot) } 0.64 \mathrm{~W} / \mathrm{mK}\end{array}$ \\
\hline $\begin{array}{c}\text { Thermal conductivity } \\
\text { of pipe }\end{array}$ & $k_{1}$ & $0.02 \mathrm{~W} / \mathrm{mK}$ \\
\hline $\begin{array}{c}\text { Thermal conductivity } \\
\text { of insulation material }\end{array}$ & $k_{2}$ & $2.0 \mathrm{~W} / \mathrm{mK}$ \\
\hline $\begin{array}{c}\text { Thermal conductivity } \\
\text { of soil }\end{array}$ & $k_{G}$ & \\
\hline
\end{tabular}

Table 2: Calculation conditions.

\begin{tabular}{|c|c|r|}
\hline Arbitrary constant & Symbol & \multicolumn{2}{|c|}{ Value } \\
\hline Grid interval & $\Delta x$ & $4 \mathrm{~m}$ \\
\hline Integration time interval & $\Delta t$ & $1 \mathrm{~s}$ \\
\hline $\begin{array}{c}\text { Boundary condition of } \\
\text { ground surface temperature }\end{array}$ & $T_{G}$ & $\begin{array}{r}\text { summer) } 300 \mathrm{~K} \\
\text { winter) } 280 \mathrm{~K}\end{array}$ \\
\hline Burial depth of pipe & $R_{G}$ & 3 or $6 \mathrm{~m}$ \\
\hline
\end{tabular}

Table 3: Arbitrary reference values.

\begin{tabular}{|c|c|r|}
\hline Reference constant & Symbol & \multicolumn{1}{|c|}{ Value } \\
\hline Reference velocity & $\bar{U}$ & $3.6 \mathrm{~m} / \mathrm{s}$ \\
\hline Reference length & $\bar{R}$ & $0.45 \mathrm{~m}$ \\
\hline Reference pressure & $\bar{P}_{1}, \bar{P}_{2}$ & $530,780 \mathrm{kPa}$ \\
\hline $\begin{array}{c}\text { Reference } \\
\text { temperature }\end{array}$ & $\bar{T}_{1}, \bar{T}_{2}$ & $\begin{array}{r}\text { cold) } 279.15,285.15 \mathrm{~K} \\
\text { hot) } 320.15,313.15 \mathrm{~K}\end{array}$ \\
\hline
\end{tabular}

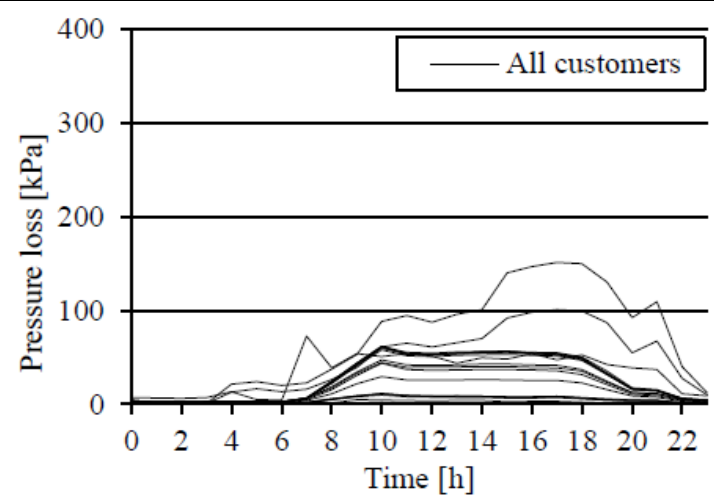

Figure 8: Cold water pressure loss through supply and return conduit on the summer peak.

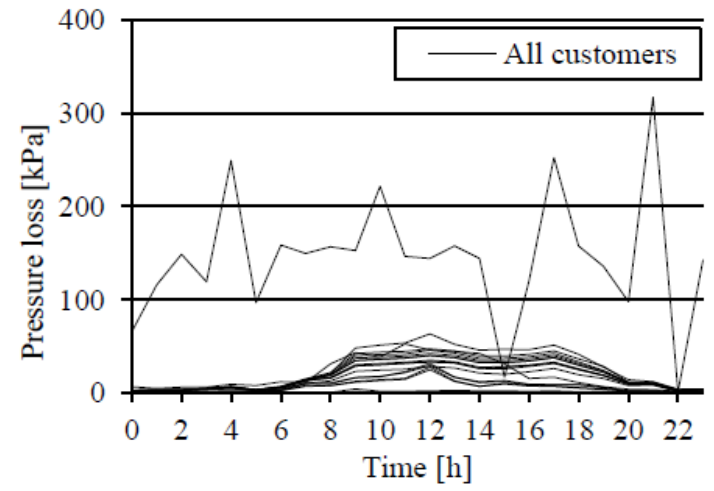

Figure 9: Hot water pressure loss through supply and return conduit on the winter peak. 


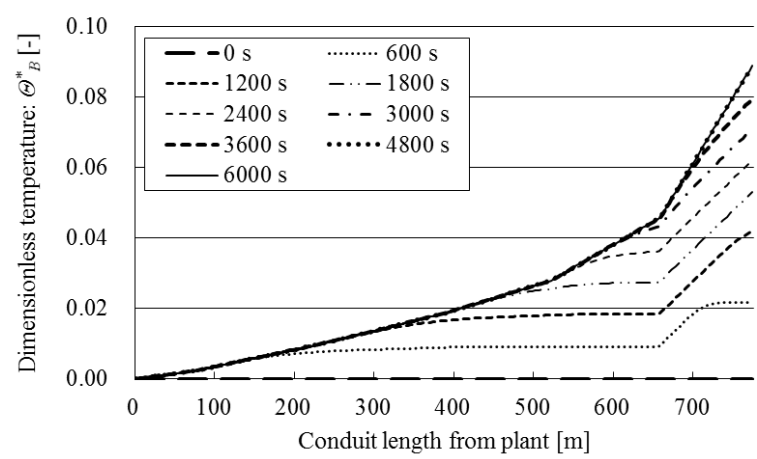

Figure 10: Cold water temperature loss through supply conduit on the summer peak: $3 \mathrm{~m}$ deep, non-insulated.

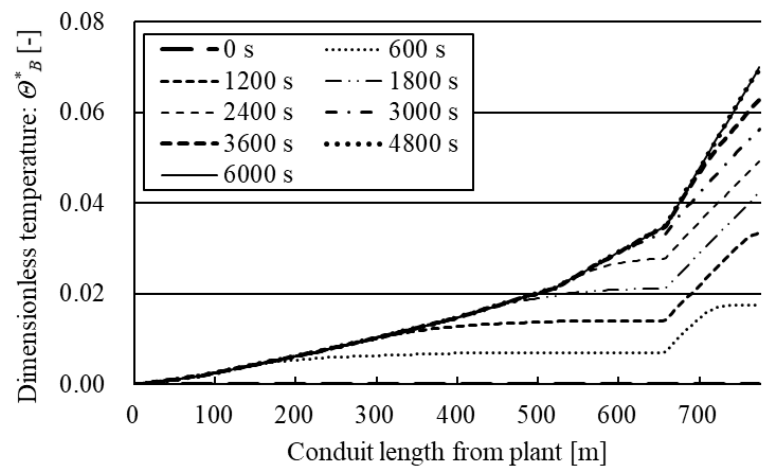

Figure 11: Cold water temperature loss through supply conduit on the summer peak: $6 \mathrm{~m}$ deep, non-insulated.

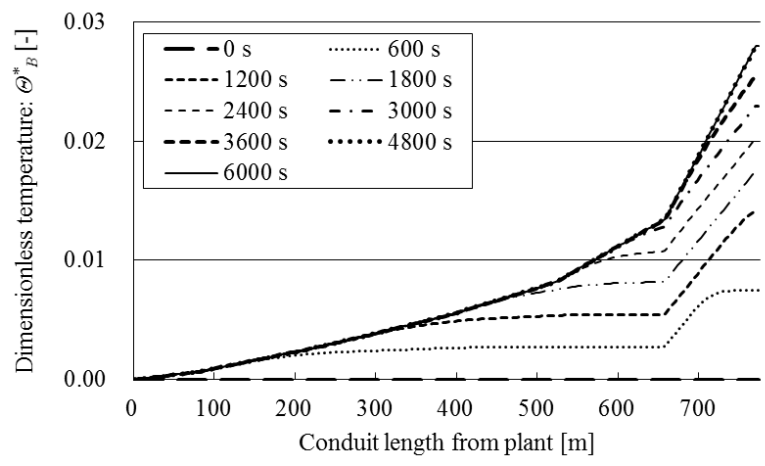

Figure 12: Cold water temperature loss through supply conduit on the summer peak: $6 \mathrm{~m}$ deep, insulated.

In current operation, the constant differential pressure control has been conducted, which would cause decrease of the opening of pressure control valves at customer receiving facilities. By optimization of supply header pressure and maximization of the opening of pressure control valves, a significant reduction of pump water power could be expected. Even on the summer peak load time, the velocity is very slow at all sections, which is around or under $1 \mathrm{~m} / \mathrm{s}$. On the supposition that the sum of pressure loss at customer facility and plant should be 300 $\mathrm{kPa}$, the pump head of cold water is required to be less than $450 \mathrm{kPa}$, which is about 60 percent of the current pump head controlled to be $720 \mathrm{kPa}$. The improvement of control method of water supply system enables further energy saving.

\section{Temperature loss}

For temperature in regional conduit, simulation results

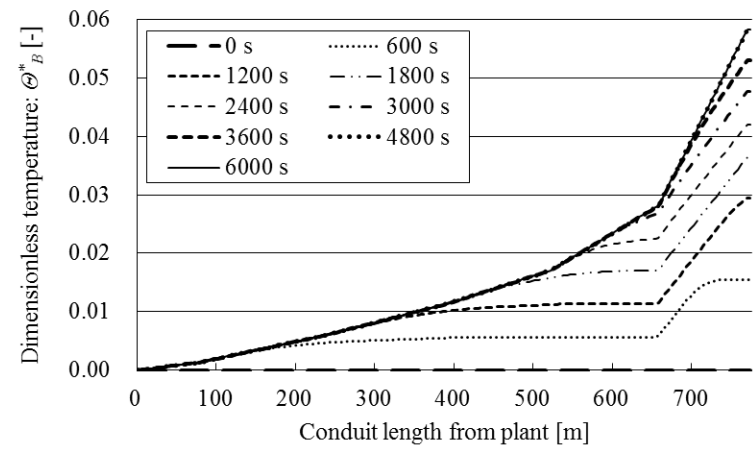

Figure 13: Hot water temperature loss through supply conduit on the winter peak: 3 m deep, insulated.

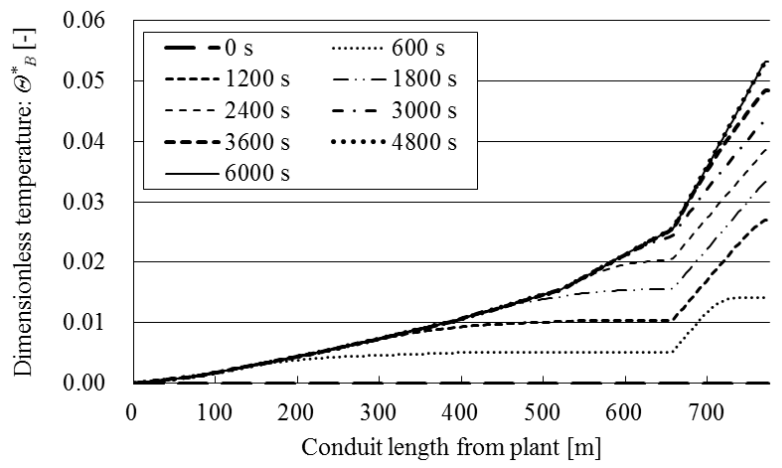

Figure 14: Hot water temperature loss through supply conduit on the winter peak: $6 \mathrm{~m}$ deep, insulated.

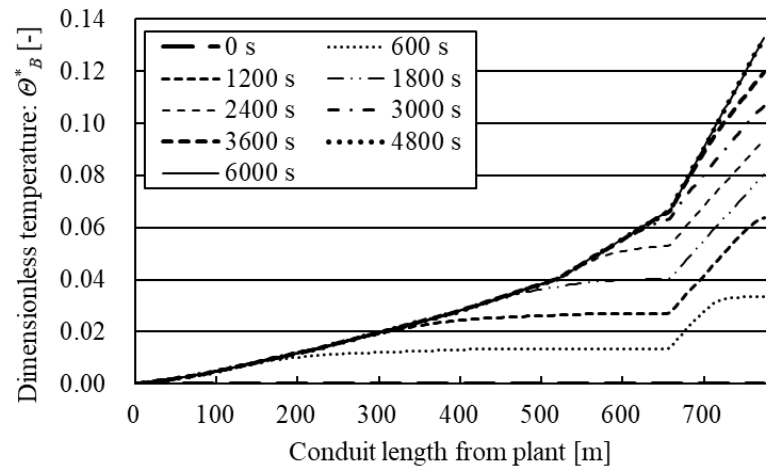

Figure 15: Hot water temperature loss through supply conduit on the winter peak: $6 \mathrm{~m}$ deep, non-insulated.

indicate that a temperature loss rate throughout main conduit is small, whereas a temperature loss rate at terminal conduit just before customer receiving facility is large. In Figure 10 to 15, based on the peak load, the time change of spatial temperature distribution in only supply conduit with the initial condition that water temperature in all sections is the same of supply temperature is plotted. The differences of temperature loss due to burial depth and presence or absence of insulation are simulated for the end customer in the west area.

For the difference due to depth, in the case of $3 \mathrm{~m}$ deep, cold water temperature loss is totally $0.54 \mathrm{~K}$ including $0.28 \mathrm{~K}$ loss through main conduit (Figure 10). In the case of $6 \mathrm{~m}$ deep, cold water temperature loss is totally $0.42 \mathrm{~K}$ including $0.21 \mathrm{~K}$ loss through main conduit (Figure 11).

For hot water, in the case of $3 \mathrm{~m}$ deep, temperature loss is totally $0.41 \mathrm{~K}$ including $0.20 \mathrm{~K}$ loss through main conduit 
(Figure 13). In the case of $6 \mathrm{~m}$ deep, temperature loss is totally $0.37 \mathrm{~K}$ including $0.18 \mathrm{~K}$ loss through main conduit (Figure 14). Because the current cold water piping is not insulated, and the hot water piping is insulated, the difference due to burial depth affects cold water conduit more than hot water conduit.

For the difference due to presence or absence of insulation, in the case of insulation of cold water conduit, temperature loss is totally $0.17 \mathrm{~K}$ including $0.08 \mathrm{~K}$ loss through main conduit (Figure 12). In the case of non-insulation of hot water conduit, temperature loss is totally $0.93 \mathrm{~K}$ including $0.46 \mathrm{~K}$ loss through main conduit (Figure 15). By insulation, temperature loss could be reduced by 60 percent for cold water (from $0.42 \mathrm{~K}$ to $0.17 \mathrm{~K}$ ) and also 60 percent for hot water (from $0.93 \mathrm{~K}$ to $0.37 \mathrm{~K}$ ).

In Figure 16, on the assumption that the cold water flow volume is half the summer peak volume at all sections, the time change of spatial temperature distribution is plotted, which could be compared with Figure 11. Because of half velocity, arrival time doubles, and heat flux increases. In the case of $6 \mathrm{~m}$ deep without insulation, temperature loss is totally more than $0.7 \mathrm{~K}$ including about $0.4 \mathrm{~K}$ loss through main conduit. By cold water flow volume halved, temperature loss could be doubled, which is a very significant problem especially in summer night and middle season.

Because the diameter of main piping is large, the thermal resistance is large, and the temperature gradient is gentle until customer receiving piping separates from main conduit. Cold water temperature rises through main conduit, and the same temperature does to end customer. Hot water temperature drops through main conduit, and the same temperature does to end customer. The temperature loss at small diameter pipe occupies nearly half of the whole temperature loss in supply conduit. Due to overdesign of piping, the velocity is slow, and the total heat input is large because of long arrival time to end customer. However, the large diameter conduit enables the pressure loss to be very small, which is trade-off relationship.

\section{Discussion}

Results of pressure loss inside regional conduit remark that supply pump water power could be extremely reduced by optimal pump control. The necessity of variable head control by inverter pump is signified for effective water supply. In DHC design, although estimation of future heat demand of customers is a very important factor, excessive piping and pumps tend to be introduced because of excessive heat source machines compared to real heat load. In this study, the pressure and temperature distribution in regional conduit is simulated. Particularly, the burial depth, presence or absence of insulation, and velocity affects temperature loss. By analysis of flow balance and energy loss, an operational control method for all customers as well as the end customer could be considered in the next step. Furthermore, by development of the whole DHC system model including plants and customers, an optimal management method should be also discussed.

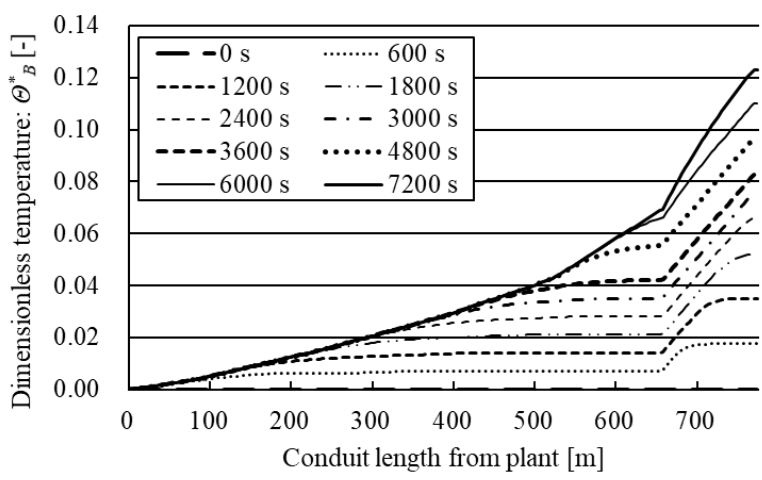

Figure 16: Cold water temperature loss through supply conduit: 6 m deep, non-insulated, half peak velocity.

\section{Conclusion}

The energy loss problem of regional conduit is a very important challenge in DHC. In this study, pressure and temperature loss in underground buried regional conduit is focused, which has not been analysed in detail in previous studies on DHC. By pressure and temperature analysis in the whole regional conduit, a trade-off relationship between pressure and temperature in control optimization becomes obvious. Some previous studies conclude that water return temperature change contributes to energy saving (Castro Flores et al., 2017; Perez-Mora et al., 2018). The heat supply agreement of the target DHC plant says that the supply header pressure should be 0.53 $0.78 \mathrm{MPa}$ for cold and hot water. In order to propose a new management method for further energy saving based on this study, the supply agreement, particularly for pressure, should be modified in the future.

\section{Acknowledgement}

We gratefully thank Fukuoka Energy Service Co., Inc. for providing invaluable operational data.

\section{References}

Castro Flores, J. F., Lacarriere, B., Chiu, J. N. W., and Martin, V. (2017). Assessing the Techno-economic Impact of Low-temperature Subnets in Conventional District Heating Networks. Energy Procedia 116, 260272.

Doyama, T., Kondo, M., Imaoka, H., Sumiyoshi, D., Kitayama, H., Lim, J., and Akashi, Y. (2018). Conduit Pressure Analysis and Renewal Effect of a District Heating and Cooling Plant. Proceedings from ASim2018: 4th Asia Conference of International Building Performance Simulation Association. Hong Kong, 3-6 December 2018.

Doyama, T., Kondo, M., Imaoka, H., Sumiyoshi, D., Kitayama, H., Lim, J., and Akashi, Y. (2018). Development of Optimal Heat Source System toward Renewal of a District Heating and Cooling Plant, Part 2: Renewal Project Outline. Proceedings from SHASEJ2018: 2018 Annual Meeting of Society of Heating, Air-Conditioning, and Sanitary Engineers of Japan. Nagoya (Japan), 12-14 September 2018. 
Kondo, M., Doyama, T., Imaoka, H., Sumiyoshi, D., Kitayama, H., Lim, J., and Akashi, Y. (2018). Development of Optimal Heat Source System toward Renewal of a District Heating and Cooling Plant, Part 1: Recent Operational Performance Report. Proceedings from SHASEJ2018: 2018 Annual Meeting of Society of Heating, Air-Conditioning, and Sanitary Engineers of Japan. Nagoya (Japan), 12-14 September 2018.

Nakayama, A., Kuwahara, F., and Kyo, K. (2002). Thermal hydraulics: From Fundamentals to Numerical Simulation (in Japanese). Kyoritsu Shuppan. Tokyo (Japan).

Perez-Mora, N., Lazzeroni, P., Martinez-Moll, V., and Repetto, M. (2018). Optimal DHC Energy Supply Harnessing Its Thermal Mass. Applied Thermal Engineering 133, 520-531. 